\title{
GYNECOLOGIC GRAFT-VERSUS-HOST DISEASE
}

\author{
Lenira Mauad' ${ }^{1}$, Andrea Novaes ${ }^{2}$ \\ 1 Hospital Amaral Carvalho - Jau. (SP) - 2 Hospital Israelita Albert Einstein (HIAE)
}

\section{GYNECOLOGICAL ADJUVANT THERAPY}

The incidence of genital GVHD varies according to published studies, ranging of $24.9 \%$ to $69 \%$ of the HSCT recipients affected. ${ }^{[1-5]}$ However, it is likely that this prevalence is underestimated because it only included patients who reported symptoms, and there might be underreporting. ${ }^{[3]}$

The median time to presentation of genital symptoms ranges from 7 to 10 months after transplantation; whereas, late-onset is not uncommon after one year. It is usual for oligosymptomatic patients who are sexually inactive to have a slow/delayed diagnosis if there is no systematic genitals examination, risk factors valuation, and preventive guidance. ${ }^{[2,7]}$

The pre-transplant clinical evaluation of women includes recommendations about genital GVHD, including early manifestations and complications and the importance of regular gynecological check-ups to help prevent severe gynecological complications, which often can become irreversible and have a significant negative impact on the quality of life..$^{[8]}$

\section{RISK FACTORS FOR FEMALE GENITAL GVHD}

The main risk factor for the development of genital GVHD is the use of peripheral blood as the source of the progenitor cells for the transplant, representing a risk three times higher than that obtained from bone marrow cells ${ }^{[.9]}$

Type of conditioning, donor, parity, age, and presence of vaginal infection at the time of transplantation do not appear to have an impact on the incidence of genital GVHD. ${ }^{[8]}$ However, oral mucosa and/ or ocular conjunctiva involvement, as well as extensive areas of skin, are signs of genital injuries by the association ${ }^{[9]}$

\section{CLINICAL FEATURES}

In $68 \%$ of cases, the symptoms affect only the vulva, whereas, in $26 \%$, both the vulva and the vagina are involved, so in that case, vulvar lesions usually precede the vaginal lesions. ${ }^{[8]}$ Isolated vaginal involvement is very rare and often asymptomatic, which makes limiting sequelae more common. ${ }^{[9]}$

The time lag between the start of vulvar and vaginal symptoms offers an opportunity to start prophylactic measures to prevent the occurrence of more severe complications, such as vaginal stenosis, with consequent impairment of sexual function. ${ }^{[3,8]}$

The genital GVHD symptoms may include dysuria, vaginal and vulvar dryness, vulvar buring, sensitivity of the vulva and vaginal introitus to touch or when washing, vulvar pain, vaginal bleeding after intercourse, and dyspareunia. ${ }^{[6,10,11]}$

Discharge is mentioned by $25 \%$ of patients with vaginal involvement, especially in the early stages, but in its mild form, it may be asymptomatic and detected only in the gynecological exam. ${ }^{[3]}$

Vulvar dryness is reported by up to $80 \%$ of women with genital GVHD and dyspareunia by up to $50 \%$ of them, impacting sexual activity. ${ }^{[3]}$ Introital pain results from inflammation of the vestibular glands openings (Bartholin's and Skene's glands), erosions or vulvar fissures, and less frequently, from labial fusion. Deep dyspareunia occurs in patients with synechiae or vaginal shortening. Amenorrhea and pelvic pain, especially in women with cyclic hormone replacement, might be a vaginal synechiae sign or internal and/or external cervix os stenosis, resulting in hematocolpos and hematometra, and they are considered severe symptoms, respectively. ${ }^{[12,13]}$ 
TABLE 1 - Graft-versus-Host Disease main symptoms and signs in the Female Genital Tract

\begin{tabular}{|c|c|}
\hline Symptoms & Signs \\
\hline \begin{tabular}{c|} 
- Vulvar and vaginal dryness \\
- Vulvar hyperemia \\
- Discharge \\
- Dyspareunia \\
- Dysuria
\end{tabular} & - Vulvar erosions and fissures \\
- Postcoital bleeding & - Labial Fusion \\
- Sensitivity and pain on touch the vulva. & - Leukeratoses \\
& - Complete vaginal occlusion \\
\hline
\end{tabular}

The findings at physical examination resemble the symptoms of erosive lichen planus, and in the early stages, it can see erosions, erythema and tenderness around Bartholin's and Skene's glands with increased pain sensitivity apart from interlabial fissures. ${ }^{[9]}$

Since other mucous membranes' involvement might increase genital involvement risk, women with oral and/or ocular involvement need to be submitted to gynecological examination even if asymptomatic. If a gynecologist is not available, the clinician should perform the physical examination, although vaginal involvement may be underdiagnosed. ${ }^{[9]}$

In the later stages, the studies include loss of vulvar architecture caused by labial adhesions narrowing of the vaginal introitus, clitoral agglutination, vaginal sinechiae, and circumferential fibrous banding. There may be decreased elasticity and shortening of the vaginal canal, mainly synechiae, making it difficult or impossible to visualize the cervix and get Pap test. These symptoms also make sexual intercourse diffi- cult or impossible'. GVHD main signs and symptoms in the female tract genitals summarized in Table 1.

Histological confirmation is recommended only in the absence of diagnostic manifestations of GVHD in other organs. The early and later stages with functional sequelae must be adequately corrected the estrogenic deficiency caused by a chemo-induced ovarian failure. So that the GVHD findings on physical examination are not confused with hypoestrogenism sign ${ }^{[1,14]}$.

\section{GVHD FEMALE GENITAL CLINICAL CLASSIFICATION}

According to the clinical score for organ evaluation described in Table 2, genital impairment can be classified as mild, moderate, or severe.

Jagasia and his collaborators developed a consensus for GVHD's diagnosis and a severity score, adapted and published by Kornik and his collaborators, suggesting active research on asymptomatic cases ${ }^{[15]}$.

TABLE 2 - Diagnosis and grading of genital chronic graft - versus-host disease - National Health Guidelines.15

\begin{tabular}{|c|c|c|c|c|}
\hline & EO & E1 & E2 & E3 \\
\hline \multirow[t]{2}{*}{ Genital Female } & No signs & $\begin{array}{l}\text { Mild signs and } \\
\text { symptomsa with or } \\
\text { without discomfort on } \\
\text { examinationb }\end{array}$ & $\begin{array}{l}\text { Moderate signs and may } \\
\text { have symptoms with or } \\
\text { without discomfort on } \\
\text { examinationb }\end{array}$ & $\begin{array}{l}\text { Severe signs with or without } \\
\text { symptoms }\end{array}$ \\
\hline & & $\begin{array}{c}\text { Any of following: } \\
\text { Erythema on vulvar } \\
\text { mucosal surfaces } \\
\text { Vulvar lichen planus-like } \\
\text { features } \\
\text { Vulvar lichen sclerosis-like } \\
\text { featuresc }\end{array}$ & $\begin{array}{c}\text { Any of following: } \\
\text { Erosive inflammatory } \\
\text { chances of the vulvar } \\
\text { mucosad } \\
\text { Ulcersd } \\
\text { Fissures in vulval folds d }\end{array}$ & $\begin{array}{c}\text { Any of the following: } \\
\text { Labial fusionc } \\
\text { Clitoral hood agglutinationc } \\
\text { Vaginal scaring c } \\
\text { Fibrous vaginal banding Vaginal } \\
\text { shortening } \\
\text { Synechia } \\
\text { Dense sclerotic changes } \\
\text { complete vaginal stenosis }\end{array}$ \\
\hline
\end{tabular}

a) Symptoms are not specific and can represent premature gonadal failure or infection

b) To be determined by specialist or trained medial provider; discomfort is defined as vulvar pain elicited by gentle touch with cotton swab in any of the following sites: vestibular glands, labia majora or minora.

c) Diagnostic sign.

d) Distinctive sign. 
a Symptoms are not specific and can represent premature gonadal failure or infection

$\mathrm{b}$ To be determined by specialist or trained medial provider; discomfort is defined as vulvar pain elicited by gentle touch with cotton swab in any of the following sites: vestibular glands, labia majora or minora.

c Diagnostic sign.

d Distinctive sign.

\section{PREVENTIVE MEASURES}

Hormonal therapy instituted early on, whether systemic or topical, correcting the ovarian failure caused by the use of medicines in the conditioning phase, maintains the physiological characteristics of the genital tract, facilitating early detection of symptoms of GVHD ${ }^{[16]}$.

Besides, women orientation in the pre-transplant evaluation, warning them for possible complications, its initial manifestations and probable sequelae, as well as periodic gynecological evaluation , mostly when GVHD manifests in other organs, such as oral mucosa and skin; it prevents many times irreversible sexual activity impairment, and also other gynecological complications.

It is recommended estriol as a $1 \mathrm{mg} / \mathrm{g}$ cream or 1 mg vaginal suppository, applied 2 to 3 times a week during the entire transplant phase until $D+100$ or until the beginning of systemic hormonal therapy. As it attenuates the vulvovaginal epithelium atrophy caused by ovarian failure and accentuated by corticosteroid action, it maintains vaginal lubrication and elasticity, allowing sexual activity and facilitating the early diagnosis of GVHD lesions6.

It is vital to encourage a return to sexual activities when possible after platelet normalization. Sexual activity favors vaginal GVHD early diagnosis, and it prevents synechiae formation in the early stages of manifestation. ${ }^{[1,17]}$ Using lubricated condoms relieves discomfort and protects against contamination during sexual intercourse. ${ }^{[17]}$

\section{EARLY TREATMENT}

Vulvar and vestibular lesions often appear as very sensitive erosions, even to (the underwear touching?) the touch of underwear. Ultra-potent topical corticosteroids as ointments or creams, which have better absorption and emollient action, are the most suitable at this stage. Clobetasol propionate $0.05 \%$ can be applied directly to the lesions once or twice a day until the erosions disappear, followed by tapering dose until complete suspension. A compress, or bathing in lukewarm water before administering corticosteroids facilitates their absorption. The administration of $1 \mathrm{mg} / \mathrm{g}$ estriol in the vulvar vestibule avoids atrophic changes and consequently, vaginal dryness sensation, it must be maintained to improve sexual function after controlling the condition. ${ }^{[14]}$

Support measures, such as the use of emollients and topical moisturizers, sitting in a lukewarm bath, and the application of viscous xylocaine, can ease the discomfort, particularly during sexual intercourse. ${ }^{[9,14]}$

Damage to the vaginal mucosa may include ulcerations, erosions, loose synechiae and vaginal discharge. The use of $25 \mathrm{mg}$ hydrocortisone in the form of vaginal suppository, once or twice a day, is recommended until early reevaluation in 15 to 30 days, decreasing the dose once the symptoms have been controlled and then maintaining twice-weekly administrations and gradually reducing the dose until complete suspension. Also, the use of $1 \mathrm{mg} / \mathrm{gestriol}$ in vaginal suppository or cream is recommended at least three times a week to counteract atrophy induced by hypoestrogenism and aggravated by corticosteroids. For vaginal synechiae, stenosis and narrowing prevention, patients are encouraged to regular intercourse, and if without a partner, vaginal dilator use is recommended twice a week. ${ }^{[14,18,19]}$

In a series of 11 patients, Spiryda et al.14 described the use of vaginal cream consisting of a $200 \mathrm{mg}$ oral suspension of cyclosporine diluted in an oily base twice daily for four weeks followed by weaning for two months, until suspension. They observed healing of vaginal erosions after two weeks with its concomitant use with vaginal dilators, thereby avoiding the need of surgery to correct stenosis in 4 of the 11 women studied. The seven women who underwent surgery to correct synechiae and vaginal stenosis continued to use the medicine after surgery, and in 6-12 weeks, they were able to have sexual intercourse. Only one patient showed no improvement with clinical or surgical treatment due to thick synechiae.

Another alternative, with controversial results, is topical calcineurin inhibitors, such as $0.1 \%$ tacrolimus in ointment or cream, for vulvar and vaginal use, respectively. It would have the advantage of having less thinning epidermis. However, it is poorly tolerated because it can cause significant stinging and burning effect especially when applied to inflamed or non-intact mucosa.8 Finally, local treatment asso- 
ciating corticosteroid and estrogen appeared to decrease the progression from mild to severe lesions, preventing surgical treatment. Thus, the earlier the treatment, the lower the sequelae rate. ${ }^{[17]}$

\section{TREATMENT OF LATE COMPLICATIONS}

Late complications, such as adhesions and occlusions in various segments of the genital tract, can be separated manually or incised under anesthesia with subsequent use of steroids and topical estrogen therapy.20,22 Dilation and drainage or hysterectomy may be necessary in extreme cases of collections in the cervical canal and uterine cavity (hematometra). ${ }^{[23]}$

\section{SEXUALITY}

Women undergoing HSCT develop several sexual problems that are not addressed to their doctors and experienced a decline in life quality. Deyer and his collaborators observed that $66 \%$ of women reported sexual difficulties, including decreased libido in $61.6 \%$ of them. ${ }^{[24]}$

These sexual dysfunctions have multifactorial causes such as medication, depression, estrogen, and androgen deficiency, decreased energy and self-esteem. Systemic GVHD and genital involvement worsen the condition with dyspareunia and sequelae that make sexual life impossible. It is essential to take care of triggering factors and a multidisciplinary approach valuing and seeking to resolve complaints about these women's general well-being. ${ }^{[11,25]}$

Several guidelines were published in the literature for gynecological care for women undergoing HSCT, with few differences. However, all expose the importance of blocking menstrual flow, clarifying the possibility of impaired hormonal and reproductive function after conditioning, as well as guidance on the first signs of genital GVHD, periodic gynecological examination, even in asymptomatic women, getting a Pap smear test, hormonal treatment for early ovarian failure and sexual dysfunction management.

They also address pediatric patients' evaluation for GVHD signs and pubertal status, as the lack of estrogen can prevent secondary sexual characteristics development. ${ }^{[1,5,6,8,9,9,14,16,25-30]}$

Besides, the presence of a gynecologist composing the multidisciplinary team of bone marrow transplant centers is of great importance for the approach in all phases, helping in the total recovery and providing an improvement in the quality of life of transplanted women ${ }^{[31]}$ Table 3 summarizes the main precautions for GVHD management in the female genital tract. 
TABLE 3 - Graft-versus-host disease management in the female genital tract

\begin{tabular}{|c|c|}
\hline Type of intervention & Score \\
\hline \multicolumn{2}{|l|}{ Vulvar discomfort } \\
\hline $\begin{array}{l}\text { Avoid chemical and mechanical irritants (soaps and intimate hygiene products) } \\
\text { Wash the genital area with warm water, allow air circulation, and clean from front to back. } \\
\text { Apply emollient to the vulva } \\
\text { Water-based lubricants }\end{array}$ & $\begin{array}{l}\text { B4 } \\
\text { B4 } \\
\text { B4 }\end{array}$ \\
\hline \multicolumn{2}{|l|}{ Vulvovaginal symptoms and low estrogen level } \\
\hline $\begin{array}{l}\text { Topical estrogen } \\
\text { Encourage regular intercourse for sexually active women. } \\
\text { Orient vaginal dilators } 2 \text { to } 3 \text { times a week for women with vaginal narrowing, stenosis, or obliteration. }\end{array}$ & $\begin{array}{l}\text { B4 } \\
\text { B4 } \\
\text { B4 }\end{array}$ \\
\hline Topical Therapy for DECH-c Vulvovaginal & \\
\hline
\end{tabular}

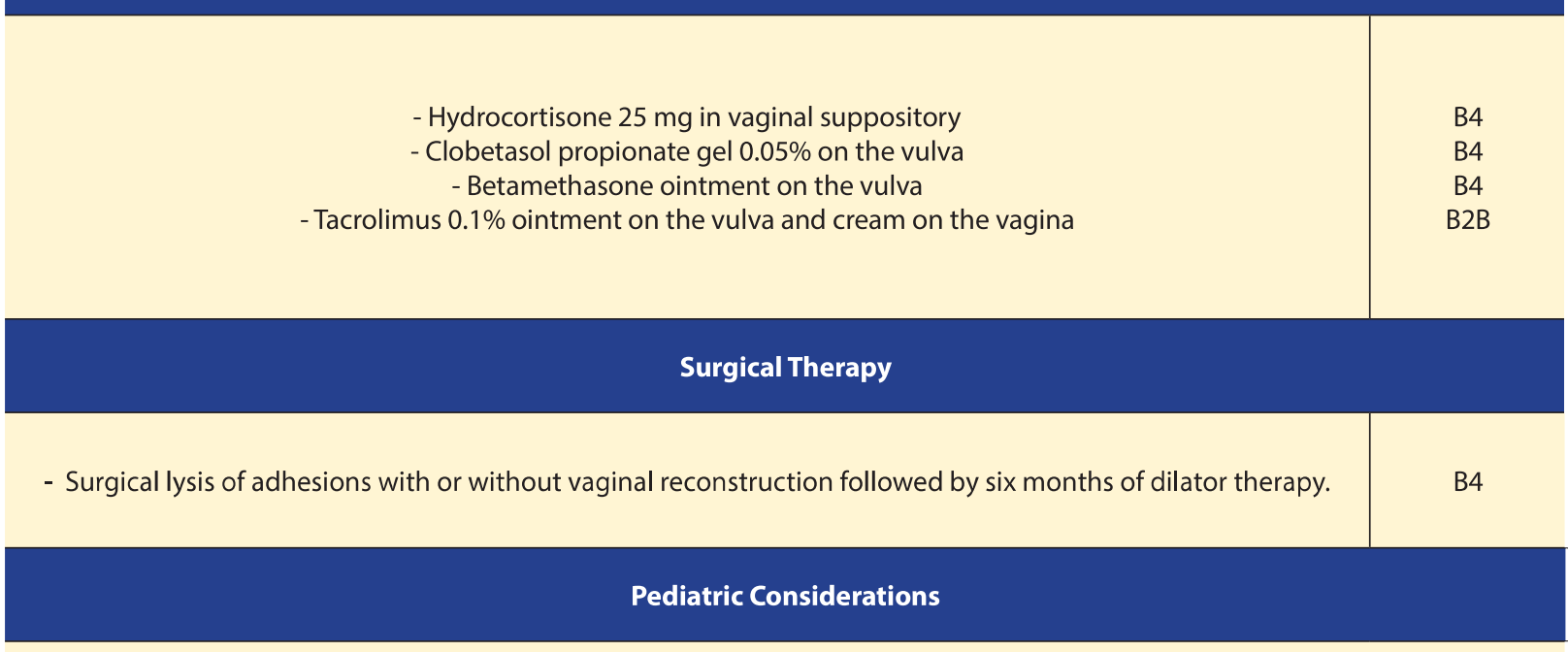

Although data on GVHD genital incidence and treatment during childhood are less reported, the valuation of the same risk factors valid for adults, and care with early management through the mother or the caregiver's guidance may avoid late diagnosis with irreversible complications. 


\section{REFERENCES}

1.Zantomio D., Grigg A.P., MacGregorL., Panek-Hudson Y., Szer J., Ayton R. Female genital tract graftversus-host disease: incidence, risk factors and recommendations for management. Bone Marrow Transplant. p. v.38, n.8, p. 567-572. 2006.

2.Spinelli S., Chiodi S., Costantini S., Van Lint M.T., Raiola A.M., Ravera G.B. Female genital tract graft-versus-host disease following allogeneic bone marrow transplantation. Haematologica. p. v. 88, n.10, p. 1163-1168. 2003.

3.Smith Knutsson E., Björk Y., Broman A.K., Helström L., Levin Jakobsen A.M., Nilsson O. Genital chronic graft-versus-host disease in females: a cross-sectional study. Biol Blood Marrow Transplant. p. v. 20, n.6, p. 806-811, 2014

4.Chung C.P., Sargent R.E., Chung N.T., Lacey J.V., Jr., Wakabayashi M.T. Graft-versus-host disease-associated vulvovaginal symptoms after bone marrow transplantation. Biol Blood Marrow Transplant. v. 22, n.2, p. 378-379, 2016.

5.Machado AMN, Hamerschlak N, Rodrigues $M$, Piccinato CA, Podgaec S, Mauad LMQ. Female genital tract chronic graft-versus-host disease: A narrative review. Hematol Transfus Cell Ther. v.41, n.1,p. 69-75, 2019. doi:10.1016/j. htct.2018.06.005

6.Shanis D., Merideth M., Pulanic T.K., Savani B.N., Battiwalla M., Stratton P. Female long-term survivors after allogeneic hematopoietic stem cell transplantation: evaluation and management. Semin Hematol. v.49, n.1, p. 83-93, 2014. 2012.

7.Stratton P., Turner M.L., Childs R., Barrett J., Bishop M., Wayne A.S. Vulvovaginal chronic graft-versus-host disease with allogeneic hematopoietic stem cell transplantation. Obstet Gynecol. p.1041-1049, 2007.

8.Frey Tirri B., Häusermann P., Bertz H., Greinix H., Lawitschka A., Schwarze C.P. Clinical guidelines for gynecologic care after hematopoietic SCT. Report from the international consensus project on clinical practice in chronic GVHD. Bone Marrow Transplant. v.50, n.1, p. 3-9, 2015.

9.Jagasia M.H., Greinix H.T., Arora M., Williams K.M., Wolff D., Cowen E.W., National Institutes of Health Consensus Development Project on Criteria for Clinical Trials in Chronic Graft-versusHost Disease: I. The 2014 Diagnosis and Staging
Working Group Report Biol Blood Marrow Transplant. p. v. 21, n.3, p. 389-401, 2015.

10.Corson SL, Sullivan K, Batzer F, August C, Storb $R$, Thomas ED. Gynecologic manifestations of chronic graft-versus-host disease. Obstet Gynecol. p. v. 60, n.4, p. 488-92, 1982.

11.Lara LA da S, De Andrade JM, Mauad LMQ, Ferrarese SR, Marana HRC, Tiezzi DG, et al. Genital manifestation of graft-vs.-host disease: a series of case reports. J Sex Med. p. v. 7, n.9. p. 3216-25.. 2010.

12.Lotery H.E., Galask R.P. Erosive lichen planus of the vulva and vagina. Obstet Gynecol. 101(5 Pt 2):1121-1125. 2003

13.Cooper S.M., Wojnarowska F. Influence of treatment of erosive lichen planus of the vulva on its prognosis. Arch Dermatol. p. v.142, n.3, p.289294, 2006.

14.Spiryda L.B., Laufer M.R., Soiffer R.J., Antin J.A. Graft-versus-host disease of the vulva and/or vagina: diagnosis and treatment. Biol Blood Marrow Transplant. v. 9. n. 12p. 760-765, 2003.

15.Kornik R I, Rustagi, LS. Vulvovaginal Graft-Versus-Host Disease. Obstet Gynecol Clin N Am v.44, n.2017, p.475-492, 2017. http://dx.doi. org/10.1016/j.ogc.2017.05.007

16. Murphy J, McKenna M, Abdelazim S, Battiwalla M, Stratton P.A Practical Guide to Gynecologic and Reproductive Health in Women Undergoing Hematopoietic Stem Cell Transplant. Biol Blood Marrow Transplant. 2019

17.Dignan F.L., Scarisbrick J.J., Cornish J., Clark A., Amrolia P., Jackson G. Organ-specific management and supportive care in chronic graft-versus-host disease. Br J Haematol. v. 158, n.1, p. 2012.

18.Jain S.P., Henry R.J. Haematocolpos following allogeneic bone marrow transplantation for chronic myeloid leukaemia. BJOG. v. 108, n.12, p. 1309-1310, 2001.

19.Anderson M., Kutzner S., Kaufman R.H. Treatment of vulvovaginal lichen planus with vaginal hydrocortisone suppositories. Obstet Gynecol. p. v. 100, n.2, p. 2002.

20.Park J., Kim T.H., Lee H.H., Chung S.H., Lee D. Gynecologic complication of chronic graft-versushost: Vaginal obstruction. Obstet Gynecol Sci. p. v.56, n.4, p. 277-280, 2013. 
21.Filipovich A.H., Weisdorf D., Pavletic S., Socie G., Wingard J.R., Lee S.J., National Institutes of Health consensus development project on criteria for clinical trials in chronic graft-versus-host disease: I. Diagnosis and staging working group report Biol Blood Marrow Transplant. v.11, n.12, p. 945-956, 2005.

22.DeLord C, Treleaven J, Shepherd J, Saso R, Powles RL. Vaginal stenosis following allogeneic bone marrow transplantation for acute myeloid leukaemia. Bone Marrow Transplant. v. 23, n.5, p. 523-5, 1999. 523-525, mar. 1999.

23.Anguenot J.L., Ibéchéole V., Helg C., Piacenza J.M., Dumps P., Bonnefoi H. Vaginal stenosis with hematocolpometra, complicating chronic graft versus host disease. Eur J Obstet Gynecol Reprod Biol. v.103, n.2, p. 185-187, 2002.

24.Dyer G, Gilroy N, Bradford J, Brice L, Klabir M, Greenwood $M$ et al. A survey of fertility and sexual health following allogenic haematopoietic stem cell transplantation in New South Wales, Australia. Br J Haematolol. v.172, p. 592- 601, 2016.

25.Hamilton BK, Goje O, Savani BN, Majhail NS, Stratton P. Clinical management of genital chronic GvHD. Bone Marrow Transplant. v.52, n.6, p. 803-810, jun., 2017.

26. Couriel D., Carpenter P.A., Cutler C., Bolaños-Meade J., Treister N.S., Gea-Banacloche J., Ancillary therapy and supportive care of chronic graft- versus-host disease: national institutes of health consensus development project on criteria for clinical trials in chronic Graft-versus-host disease: V. Ancillary Therapy and Supportive Care Working Group Report Biol Blood Marrow Transplant. v. 12, n. 4, p. 375- 396, 2006.

27.Comissão Nacional de Incorporação de Tecnologias no SUS - CONITEC- Protocolo Clínico e Diretrizes Terapêuticas Imunossupressão pós transplante de Medula Óssea 2016 http://conitec.gov. br/images/Consultas/Relatorios/2016/PCDT_ Imunossupressao_TransplanteMedulaOssea_ CP2016.pdf

28.Milroy CL, Jones KP. Gynecologic care in hematopoietic stem cell transplant patients: a review. Obstet Gynecol Surv.v.65, n.10, p. 668-679, 2010.

29.Lev-Sagie, A., Adar-Walling, E., Gumer, A. et al. Management and long-term consequences of genital graft versus host disease following hematopoietic stem cell transplantation. Bone Marrow Transplant 2020. https://doi.org/10.1038/ s41409-020-0933-2

30.Cizek SM, El-Bietar J, Rubinstein J, et al. Pediatric and Young Adult Vulvovaginal Graft-versus-Host Disease. Biol Blood Marrow Transplant. v.25, n.12, p. 2408-2415, 2019.

31. Stratton P. Gynecologic care after hematopoietic cell transplantation: a call to action to include gynecologists in the transplant team. Bone Marrow Transplantation. v.50, p. 1-2, 2015. 